\title{
Unit of Radiation Equivalent Dose
}

National Cancer Institute

\section{Source}

National Cancer Institute. Unit of Radiation Equivalent Dose. NCI Thesaurus. Code C69440.

A unit for measuring the quantity of radiation dose that expresses an assumed equal biological effectiveness of a given absorbed dose on a common scale for different types of ionizing radiation. 